\title{
Combination of Allergic Asthma Symptom and Medication Scores in Allergen Immunotherapy Trials: A Proposal
}

\author{
Raquel Caballero Alicia Grau Gracia Javaloyes Sandra del Pozo \\ Miguel-Ángel León Marta Romero Miguel Casanovas \\ Inmunotek, S.L, Alcalá de Henares, Spain
}

\section{Keywords}

Allergen-specific immunotherapy · Asthma symptom score . Asthma medication score · Inmunotherapy clinical trials . Asthma combined symptom and medication scores

Specific allergen immunotherapy (AIT) has been successfully used over 100 years to treat allergic rhinitis [1] and allergic asthma [2]. It is recognized as an effective modifier of the biological immune response [3]. The research field of AIT is continuously evolving and includes different allergen modifications, galenic presentations, adjuvants, and various routes and schedules of administration.

Randomized clinical trials must be conducted to demonstrate safety and efficacy and must follow the current guidelines [4]. For this purpose, the European Medicines Agency (EMA) released the "Guideline on the Clinical Development of Products for Specific Immunotherapy for the Treatment of Allergic Diseases" [5] stating that, in AIT trials, the primary endpoint has "to reflect both, symptom severity as well as the intake of rescue medication." However, no validated method for the evaluation of the scores of asthma symptom and medication in a single combined score is available.

Therefore, there is a need for a method which combines asthma symptom score (SS) and medication score

karger@karger.com www.karger.com/iaa

Karger"

BOPEN ACCESS
C 2021 The Author(s).

Published by S. Karger AG, Basel

This is an Open Access article licensed under the Creative Commons Attribution-NonCommercial-4.0 International License (CC BY-NC) (http://www.karger.com/Services/OpenAccessLicense), applicable to the online version of the article only. Usage and distribution for commercial purposes requires written permission.
(MS). The European Academy of Allergy and Clinical Immunology published a consensus related to the combination of symptom and MSs (CSMS) to be used in AIT trials for allergic rhinoconjuntivitis (RC) [4]. It is based on an equal weight of the total daily SS (dSS) and total daily MSs (dMSs). In this publication, the authors state as advantages the existence of a well-defined terminology of eye and nose symptoms, together with the $0-3$ Likert scale symptom score which is accepted by the EMA and the Food and Drug Administration (FDA). The dSS is the sum of all individual symptoms divided by the number of symptoms, being the range of dSS from 0 to 3 (being 3 the maximum score). The difficulty of scoring medication was solved using a stepwise of the rescue medication, based on a slight modification of the Statement of the World Allergy Organization taskforce [6].

- Step 0: no use of medication. Scored as 0.

- Step 1: use of oral and/or topical (eyes and/or nose) nonsedative antihistamines (H1A). Scored as 1.

- Step 2: use of intranasal corticosteroids with/without H1A. Scored as 2.

Raquel Caballero, Alicia Grau, and Gracia Javaloyes participated equally.

Edited by: O. Palomares, Madrid. 
Fig. 1. Proposed stepwise and scoring for asthma medication. dMS, daily medication score; SABA, short acting beta sgonist; ICS, inhaled corticosteroids; LTRA, leukotrienereceptor antagonists; LABA, long acting beta agonist.

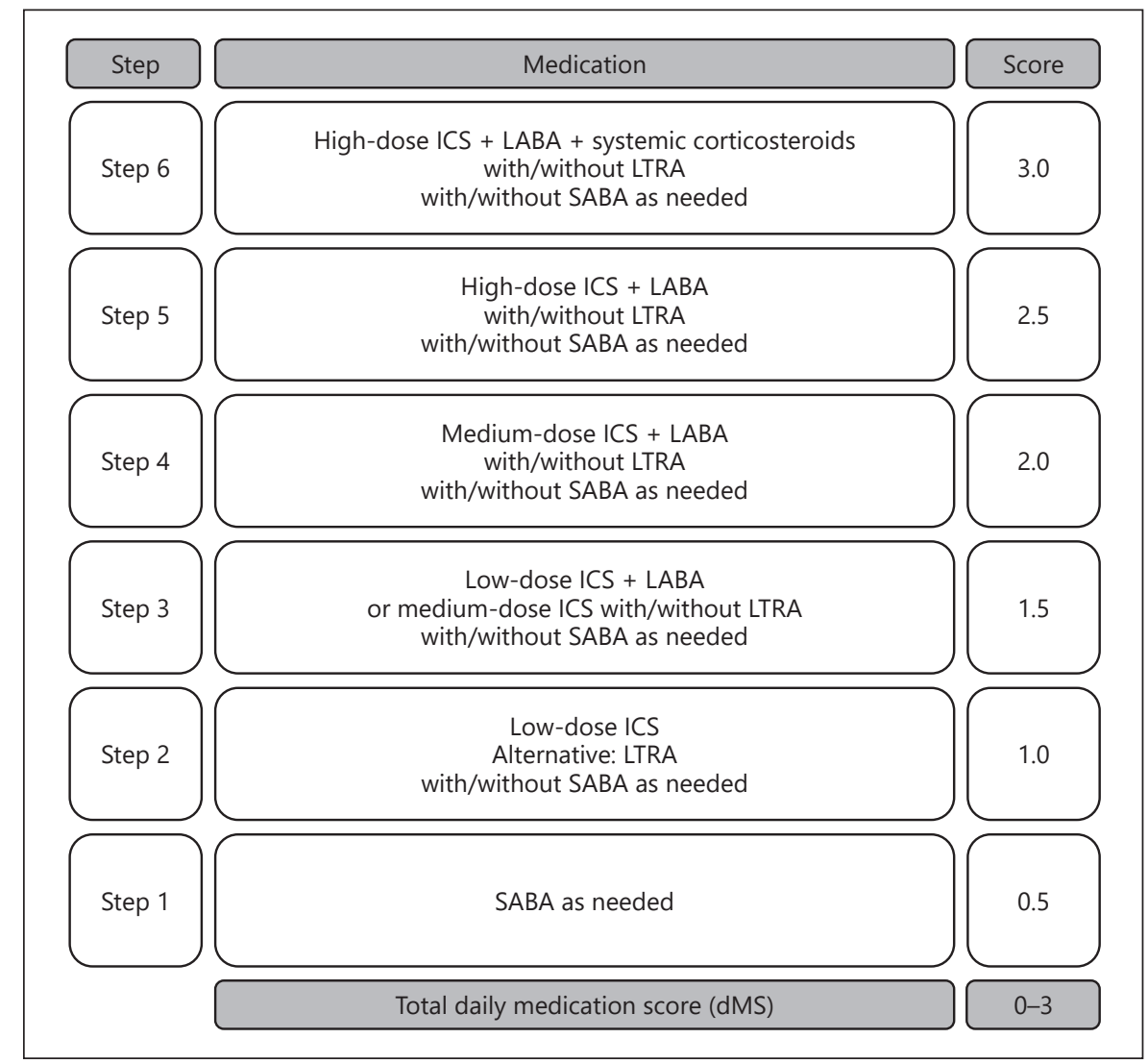

- Step 3: use of oral corticosteroids with/without intranasal corticosteroids, with/without H1A. Scored as 3. The dMS ranges from 0 to 3 . The CSMS is the sum of dSS (range 0-3) and dMS (range 0-3). Therefore, the values of CSMS are in the range of 0-6.

However, no consensus exists related to the combination of SS and MS in AIT trials for allergic asthma. There are scales like Asthma Control Test (ACT) [7] or Asthma Control Questionnaire (ACQ) [7], but they do not evaluate the medication and symptoms in a combined way.

We propose that a similar model of CSMS in AIT trials for allergic RC could be used in AIT trials for allergic asthma. Related to asthma symptoms, there are 4 well-defined and accepted symptoms in asthma: cough, wheeze, shortness of breath, and chest tightness [8,9], being the fourpoint Likert scale (0-3) used in several clinical trials for scoring these symptoms. The score is 0 for no symptoms, 1 for mild symptoms (minimal awareness and easy tolerated), 2 for moderate symptoms (definite awareness of symptom, i.e., bothersome but tolerable), and 3 for severe symptoms (symptoms which are hard to tolerate and cause interference with daily living and/or sleeping activities).
Each of the symptoms is scored from 0 to 3, considering the severity of each value. The final dSS of asthma would be the sum of all individual symptom scores divided by the number of symptoms, being the range of dSS from 0 to 3 .

Related to medication, a stepwise treatment of asthma is described in GINA [9] and GEMA [8]. We propose a stepwise dMS for medication (Fig. 1), based on GINA and GEMA, to be used in clinical trials of AIT in asthma.

The proposed asthma CSMS is the sum of dSS (range $0-3$ ) and dMS (range 0-3), being the values of CSMS in the range of 0-6 (sum of dSS and dMS). With this approach, the equal weight of the total dSS and total dMS can be achieved.

The use of this CSMS does not imply that this could substitute methods already used for the assessment of asthma control such scales like ACT [7] or Asthma Quality of Life Questionnaire (AQLQ) [10]. However, it could be a complement to evaluate the effect of AIT in asthma. In similarity with the statement of the unmet need of psychometric validation in the publication of the RC CSMS [4], this proposed asthma CSMS needs this validation too in clinical trials, which are already ongoing. 


\section{Statement of Ethics}

Not applicable.

\section{Conflict of Interest Statement}

All authors are employees of Inmunotek, S.L.

\section{Funding Sources}

The authors did not receive any funding.

\section{Author Contributions}

R.C., A.G., G.J., and M.C. have made substantial contributions to the conception of this proposal. S.d.P., M.R., and M.L. have made contributions in review and draw.

\section{References}

1 Roberts G, Pfaar O, Akdis CA, Ansotegui IJ, Durham SR, Gerth van Wijk R, et al. EAACI guidelines on allergen immunotherapy: allergic rhinoconjunctivitis. Allergy. 2018 Apr; 73(4):765-98.

2 Dhami S, Kakourou A, Asamoah F, Agache I, Lau S, Jutel M, et al. Allergen immunotherapy for allergic asthma: a systematic review and meta-analysis. Allergy. 2017 Dec;72(12): 1825-48.

3 Shamji MH, Durham SR. Mechanisms of allergen immunotherapy for inhaled allergens and predictive biomarkers. J Allergy Clin Immunol Pract. 2017 Dec 1;140(6):1485-98.

4 Pfaar O, Demoly P, Gerth van Wijk R, Bonini $S$, Bousquet J, Canonica GW, et al. Recommendations for the standardization of clinical outcomes used in allergen immunotherapy trials for allergic rhinoconjunctivitis: an EAACI Position Paper. Allergy. 2014 Jul; 69(7):854-67.

5 European_Medicines_Agency, Committee_ for_Medicinal_Products_for_Human_Use, (CPMP). Guideline on the Clinical Development of Products for Specific Immunotherapy for the Treatment of Allergic Diseases. CHMP/EWP/18504/2006 Electronic citation: www.emeaeuropa.eu/pdfs/human/ ewp/1850406enfinpdf. 2008

6 Canonica GW, Baena-Cagnani CE, Bousquet J, Bousquet PJ, Lockey RF, Malling HJ, et al. Recommendations for standardization of clinical trials with Allergen Specific Immunotherapy for respiratory allergy. A statement of a World Allergy Organization (WAO) taskforce. Allergy. 2007 Mar;62(3):317-24.
7 Schatz M, Sorkness CA, Li JT, Marcus P, Murray JJ, Nathan RA, et al. Asthma Control Test: reliability, validity, and responsiveness in patients not previously followed by asthma specialists. J Allergy Clin Immunol. 2006 Mar; 117(3):549-56

8 GEMA 5.0. Guía española para el manejo del asma. 2020. Available at https://www. gemasma.com.

9 Global_Initiative_for_Asthma. Global Initiative for Asthma (GINA). Global strategy for asthma management and prevention. 2020 update.

10 Juniper EF, Guyatt GH, Epstein RS, Ferrie PJ, Jaeschke R, Hiller TK. Evaluation of impairment of health related quality of life in asthma: development of a questionnaire for use in clinical trials. Thorax. 1992 Feb;47(2):76-83. 